\title{
POPULATION ABUNDANCE OF RED PALM WEEVIL, Rhynchophorus ferrugineus (COLEOPTERA: DRYOPHTHORIDAE) IN RHU TAPAI COCONUT PLANTATION
}

\author{
NURUL SYAFIQAH SENAFI ${ }^{\mathrm{A}}$, NOR ZALIPAH MOHAMED ${ }^{\mathrm{B}}$, AND WAHIZATUL AFZAN \\ $\mathrm{AZMI}^{\mathrm{C} *}$ \\ ${ }_{a, b, c}^{a}$ Faculty of Science and Marine Environment, Universiti Malaysia Terengganu, 21030 Kuala Nerus, Terengganu, Malaysia. \\ *Corresponding author: ${ }^{c}$ wahizatul@umt.edu.my
}

\begin{abstract}
Red Palm Weevil (RPW), Rhynchophorus ferrugineus is a lethal pest which has been described as a serious pest that reduces the production of coconut tree and other major cultivated palms. RPW infestation was initially detected by Department of Agriculture (DOA) in 2007 in all eight Terengganu districts. Rhu Tapai plantation area is one of the highly infested areas in Terengganu. Until now, limited reports on population abundance of this lethal pest have been discussed particularly in Rhu Tapai. Therefore, a study on population abundance is a must in order to understand the population dynamic of RPW which will be the first step of its control strategy. A total of 12 traps were installed and synthetic pheromones (P028 Ferrolure+) were used in attracting the RPW adults. Overall, 81 individuals of RPW were successfully collected after 16 weeks of pheromone trapping ( $3^{\text {rd }}$ September until $28^{\text {th }}$ November 2018). The trend of weekly RPW captured was eventually decreasing from Week 1 to Week 16 but showed a sudden increment in Week 10. Pandan cultivar plot captured the highest number of adult RPW compared with Mawa cultivar plots. Result showed no significant difference between RPW sexes percentage of sexes which was $53 \%$ of male and $47 \%$ of female $(1: 1$ ratio $)(U=0.143, p>0.05)$. Daily rainfall and temperature significantly reduced the trapping efficiency $\left(R_{\text {rainfall }}^{2}=0.142, p=0.145 ; R_{\text {temperature }}^{2}=0.0858 ; p=0.258\right)$. These results will be the baseline information for future study regarding control management strategy using pheromone-based mass trapping system.
\end{abstract}

Keywords: Red Palm Weevil (RPW), Rhynchophorus ferrugineus, pheromone trap, coconut, pest, Terengganu, Malaysia.

\section{Introduction}

Rhynchophorus ferrugineus (Coleoptera: Dryophthoridae) is a severe pest of major cultivated palms such as coconut palm, date palm, oil palm and sago palm (Mazza et al., 2014). This weevil is commonly known as red palm weevil (RPW) and it was first detected in 2007 by the Department of Agriculture (DOA) Terengganu in all eight districts of Terengganu state. The number of infestation sites has increased significantly to 858 localities in 2011 (Wahizatul et al., 2013) and recently in 2016, RPW has been recorded in Perlis, Kedah, Pulau Pinang, Terengganu and Kelantan which indicated a rapid spread of RPW population in Malaysia (DOA, 2016).
It has been reported that RPW attacks more than 29 palm species worldwide, and coconut palms are being the highly preferred RPW host in the South Asia (Murphy \& Briscoe, 1999; Norhayati et al., 2017). The demand for coconut fruits in Malaysia is rising, but is facing a shortage in coconut supply due to the RPW infestation. The coconut prices are up by as much as $50 \%$ since 2016 , with some traders increasing the price from RM2 to RM3 per coconut (DOA, 2016). In Terengganu state, approximately 11,220 metric tons of coconuts are produced on 2,440 ha of land, mainly along the $225 \mathrm{~km}$ of the 'Beach Ridges Sandy Soil' (BRIS) of the coastal area (DOA 2016). It has been speculated that RPW has the potential to 
attack the oil palm plantations, one of the largest economic contributors to Malaysia (Wahizatul et al. 2017), and soon the productivity of coconut trees will be decreased.

Based on DOA report (2016), Rhu Tapai coconut planting areas in Setiu district, Terengganu is one of the RPW highly infested areas in Terengganu. Pheromone based mass trapping has been incorporated into RPWIntegrated Pest Management programs and used successfully to monitor this pest in several countries such as in India (Faleiro, 2006), Saudi Arabia (Al-Saoud et al., 2010), Philippines (Hoddle \& Hoddle, 2011) and Malaysia (Sivaparagasm et al., 2010; Wahizatul et al., 2014). Thus, this study is aimed to investigate the population abundance of RPW in Rhu Tapai plantation area which will be the baseline information for future study regarding on controlling this lethal pest in Malaysia region.

\section{Materials and Methods}

\section{Site Description}

The study was conducted in the Rhu Tapai

Agriculture Station, Setiu, Terengganu ( $5^{\circ} 18^{\prime}$ 14.9292" N, $102^{\circ} 34$ ' 48.5616" E) from 3rd September until 28th November 2018 (Figure 1). The area is planted with many important crops such as coconut, watermelon, ladies finger, chilies, dragon fruit and many more. Twelve percent of this area is covered with coconut trees of different cultivars such as Mawa and Pandan. Table 1 shows the description of each plot of RPW pheromone trapping in Rhu Tapai.

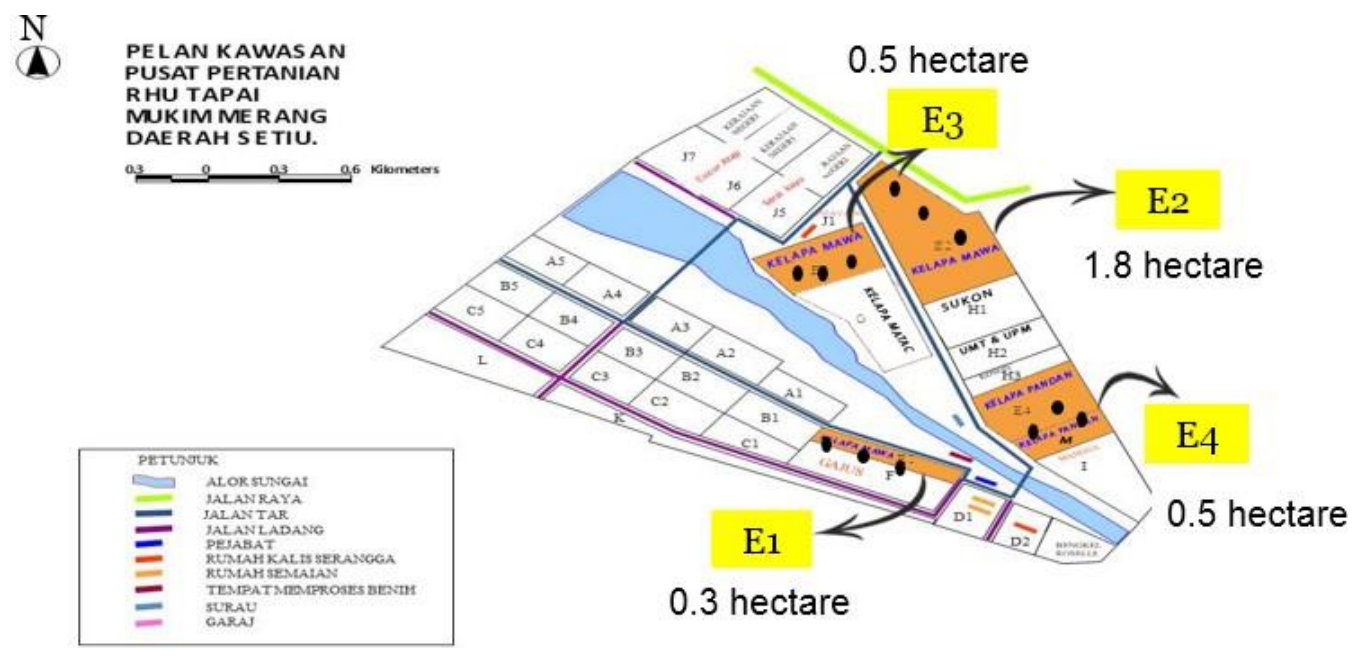

Figure 1: Rhu Tapai Agriculture Station Map. Note that the black dots represent the pheromone traps (Source: DOA, Terengganu)

$\begin{array}{lcccc}\text { Plot } & \text { Cultivar } & \begin{array}{c}\text { Age of coconut tree } \\ \text { (Year) }\end{array} & \begin{array}{c}\text { Size of plot } \\ \text { (Hectare) }\end{array} & \begin{array}{c}\text { Number of traps } \\ \text { E1 }\end{array} \text { Mawa } \\ \text { E2 } & 40 & 0.3 & 3 \\ \text { E3 } & \text { Mawa } & 30 & 1.8 & 3 \\ \text { E4 } & \text { Mawa } & 5 & 0.5 & 3\end{array}$

Table 1: Type of coconut cultivars, age of coconut trees, size of each plot and number of RPW pheromone trapping in Rhu Tapai coconut plantation area. 


\section{Pheromone Mass Trapping and Environmental Parameters}

RPW adults were collected by using standard pheromone trapping as described by Wahizatul et al., (2014) with some modifications. Each trap contained $800 \mathrm{ml}$ of tap water, $450 \mathrm{~g}$ of pineapple (act as food bait) and 700-mg ferrugineol, P028 Ferrolure+ (synthetic pheromone). The food bait was replaced every two weeks, while the tap water was replenished once a week to maintain the efficacy of moisture of the food baits. A total of 12 traps were installed in this study and the distance between the traps was approximately $80-100 \mathrm{~m}$. The traps were placed in the shaded area to obtain a sustained and uniform release of the pheromone lure into the environment. Captured RPW were checked every week. Weekly data for environmental parameters such as temperature, relative humidity and rainfall data were obtained from Department of Meteorology of Malaysia.

\section{Data Analysis}

Man-Whitney test was used to evaluate the differences of the total RPW captured between sexes, and Pearson correlation analysis was used to measure the association between total RPW captured with rainfall data, temperature and relative humidity. Kruskal-Wallis was used to compare the differences of total number of captured RPW between weekly of trapping and study plots. All statistical analyses were conducted with SPSS 21.0 statistical software.

\section{Results and Discussion}

\section{Weekly Trap Catches of RPW}

A total of 81 individuals of RPW were collected during 16 weeks of trapping. Figure 2 shows the highest number of RPW captured was in the early week of sampling (Week 1 until Week 4) as compared to the end of sampling week. The highest number of captured RPW was in Week 3 (15 individuals), but then it started to decrease until Week 7, where no RPW was captured. The weekly trap catches then started to increase in
Week 10 but gradually decreased in Week 11 until Week 16. However, no RPW was captured in Week 14. There was a significant difference of total captured RPW between weekly trap catches (Kruskal-Wallis $=1.253 ; \mathrm{p}<0.05)$.

The trend of weekly catches was decreasing due to the massive clearance of all infected coconuts by DOA Terengganu in Week 5 , where there was a drastic drop of the total captured RPW in the early of sampling week. Mahmud et al. (2015) stated that host plant is crucial to RPW for their development and reproduction. Adult RPW may fly away to find another host as their food source in order to survive. The result also showed a sudden decreased of the total captured RPW in Week 16 which was the end of sampling week. This is due to the heavy rainfall that can reduce the trapping efficiency. Haris et al. (2014) reported that pheromone dispenser released low volatiles from the food baits and ferrugineol during higher rainfall and low sunshine which means heavy rainfall clearly will affect the trapping performance. Besides massive clearance and heavy rainfall, trap disturbance made by animals such as monkeys and cows also was one of the factors that reduced the trapping catches of RPW.

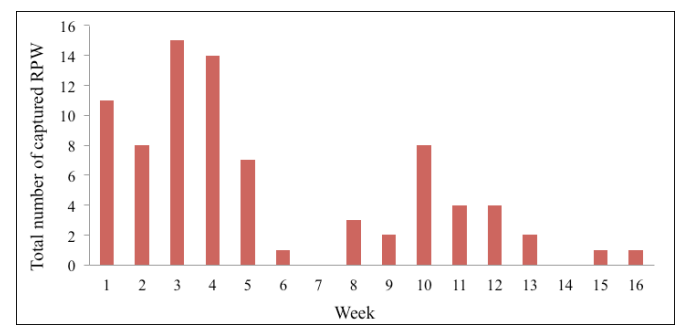

Figure 2: Weekly trap catches of RPW in Rhu Tapai Agricultural Station. (* Massive clearance where all infected coconut trees were cut down by DOA)

Interestingly, the highest number of captured RPW was in Trap 1 followed by Trap 2 and Trap 3 which were located at Pandan cultivar plot (Figure 3). There were 20 individuals of RPW captured in Trap 1, while Trap 2 and Trap 3 captured 14 and 9 individuals respectively. Meanwhile, Traps 9 and 12 only captured 1 individual in the trap throughout the trapping period. 


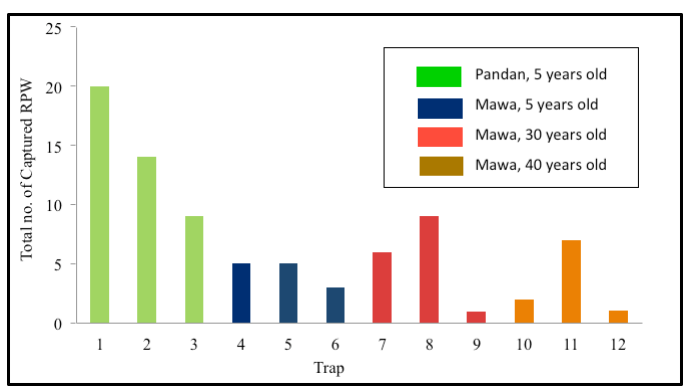

Figure 3: Total number of captured RPW according to trap number and plot area

In this study, Pandan cultivar (Plot E4) was the most preferred coconut cultivar and the age of the coconut is considered matured and productive. Even though the total number of Mawa cultivar trees are higher than Pandan cultivar, the result of the total captured RPW clearly showed a huge difference. Although age of Mawa cultivar in Plot E3 and Pandan cultivar in Plot E4 was similar (5 years old), traps in Plot E4 captured significantly greater than Plot E3 as well as other plots which have 30 to 40 years old of Mawa coconuts $(\mathrm{p}<0.05)$. It has been reported that RPW easily penetrated the young and fresh palms than old palms due to soft succulent stem (Cabello, 2006). Besides that, it is presumed that volatiles produced from Pandan cultivar strongly attracted RPW compared with other coconut cultivars. However, little is known about the preferred coconut cultivar of RPW. As such, it is suggested that further study is needed to investigate whether RPW are more preferred Pandan cultivar as compared to Mawa cultivar.

In terms of sex ratio, the percentage of male RPW was higher as compared to female RPW. There was a little difference between percentage of sexes which was $53 \%$ of male and $47 \%$ of female. Man-Whitney test shows no significant difference between RPW sexes $(U=0.143, p>$ 0.05). Thus, the ratio for the RPW sexes was 1 female: 1 male because of no significant difference detected between sexes. In previous studies, Abbas et al. (2006), Sivapragasm et al. (2010) and Haris et al. (2014) reported that the number of captured RPW females were higher as compared to male. The number of females captured higher might be due to females need to find food source for their young (Haris et al., 2014). However in this study, it shows that the percentage of male RPW (53\%) was higher as compared to female RPW (47\%) and the ratio was 1 female: 1 male. Males were more captured as compared to female probably due to adult female RPW had flew away from that area in order to find food source for their development and reproduction during massive clearance.

\section{Influence of Environmental Parameters on the Total Numbers of Captured RPW}

Figure 4A displays a positive strong correlation between total number of captured RPW captured and the amount of rainfall data $\left(\mathrm{R}^{2}\right.$ $=0.142, \mathrm{p}=0.145)$. Similarly, temperature was found positively correlated between total number of captured RPW $\left(\mathrm{R}^{2}=0.0858 ; \mathrm{p}=\right.$ 0.258) (Figure 4B). However, there was a weak negative correlation between the total number of captured RPW and humidity $\left(\mathrm{R}^{2}=0.1264, \mathrm{p}>\right.$ 0.05) (Figure 4C).

Haris et al. (2014) reported that seasonally changing in weather patterns could be associated with RPW mobility and pheromone mass trapping performance. A study conducted at Al-Qteef, Saudi Arabia found that the weevil activity was high during summer and low during winter (Vidyasagar et al., 2000) which reveals that environmental parameters play an important role in the implementation of pheromone mass trapping of RPW. Two studies from Malaysia, Haris et al. (2014) and Wahizatul et al. (2014) showed that lower numbers of RPWs were collected during high rainfall but the numbers increased during hot sunny days. In this study, it was found that temperature and rainfall influenced the numbers of RPW captured even though the correlation was considered low. It was clear that high numbers of RPW were collected during less rainfall and high temperature (range $26-28^{\circ} \mathrm{C}$ ). Thus, these ecological factors could be very useful in forecasting and predicting RPW population dynamics. 

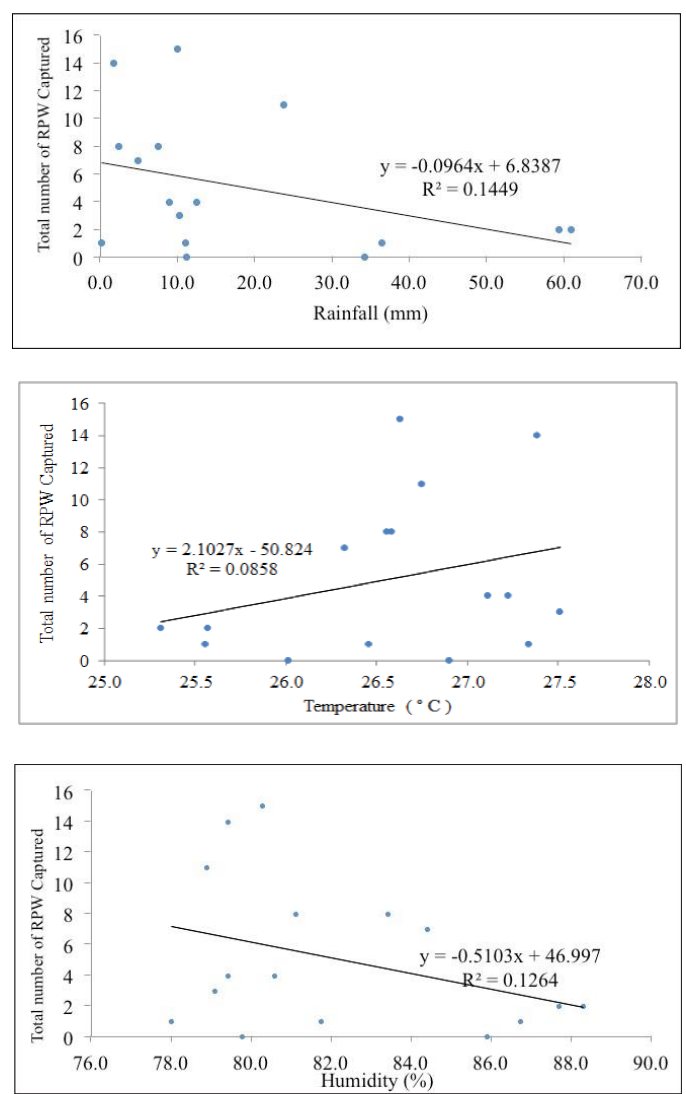

Figure 4: The correlation analysis between total numbers of captured RPW captured and weekly rainfall (A), temperature (B) and humidity (C) data

\section{Conclusion}

Further action is needed to control RPW population at Rhu Tapai Agricultural Station. The pheromone-based mass trapping is important and one of the most practical technique to monitor the population abundance of RPW. Besides, environmental parameters also play an important role in the implementation of pheromone mass trapping of RPW for predicting the RPW population dynamic. Even though only 12 traps were installed at the Rhu Tapai Agriculture area, it is hoped that the outcome of this study will be the baseline information for future study regarding control management strategy using pheromone-based mass trapping system. However, further study is required to ensure that the population abundance is more accurate for the RPW status in Rhu Tapai coconut plantation area.

\section{Acknowledgements}

This work is supported by the UKM-Sime Darby Research-UMT fund (Vot: 53235). The authors would like to thank Department of Agriculture of Terengganu State for allowing us to conduct this study in Rhu Tapai Agricultural Station. The authors are also thankful to Universiti Malaysia Terengganu for providing the laboratory and transport facilities.

\section{References}

Abbas, M. S. T., Hanounik, S. B., Shahdad, A. S., \& Ai-Bagham, S. A. (2006). Aggregation pheromone traps, a major component of IPM strategy for the red palm weevil, Rhynchophorus ferrugineus in date palms (Coleoptera: Curculionidae). Journal of Pest Science, 79(2), 69-73.

Al-Saoud, A., Al-Deeb, M., \& Murchie, A. (2010). Effect of color on the trapping effectiveness of red palm weevil pheromone traps. Journal of Entomology, 7 (1), 54-59.

Cabello, T. (2006). Population biology and dynamic of the red palm weevil, Rhynchophorus ferrugineus (Olivier, 1790) (Coleoptera: Dryophthoridae) in Spain. In: I Jornada Internacionalsobreel Picudo Rojodelas Palmeras, Moncada, Spain.

DOA (Department of Agriculture) (2016). Report on current status of Red Palm Weevil, Rhynchophorus ferrugineus in Terengganu. Biosecurity Division Department of Agriculture, Government Press, Malaysia.

Faleiro, J. R. (2006). A review of the issues and management of the red palm weevil Rhynchophorus ferrugineus (Coleoptera: Rhynchophoridae) in coconut and date palm during the last one hundred years. International Journal of Tropical Insect Science, 26(3), 135-154. 
Haris, M. H., Nang, M. L. S., Chuah, T. S., \& Wahizatul, A. A. (2014). The efficacy of synthetic food baits in capturing red palm weevil, Rhynchophorus ferrugineus (Coleoptera: Curculionidae) in campus area of Universiti Malaysia Terengganu. Serangga, 19(1), 19-35.

Hoddle, M. S., \& Hoddle, C. D. (2011). Evaluation of three trapping strategies for red palm weevil, Rhynchophorus ferrugineus (Coleoptera: Curculionidae) in the Philippines. Pakistan Entomology, 33(2), 77-80.

Mahmud, A. I., João, F., \& Eleonore, R. A. V. (2015). Red palm weevil (Rhynchophorus ferrugineus Olivier, 1790): Threat of palms. Journal of Biological Sciences, 15(2), 5667.

Mazza, G., Francardi, V., Simoni, S., Benvenuti, C., Cervo, R., Faleiro, J. R., \& Roversi, P. F. (2014). An overview on the natural enemies of Rhynchophorus palm weevils, with focus on R. ferrugineus. Biological Control, 77, 83-92.

Murphy, S. T., \& Briscoe, B. R. (1999). The red palm weevil as an alien invasive: biology and the prospects for biological control as a component of IPM. Biocontrol news and information, 20, 35-46.

Norhayati, Y., Wahizatul, A. A., Siti Nor Jannah, S. \& Nurul Wahidah, M. R. (2017). Antioxidative response of Cocos nucifera against infestation by the red palm weevil (RPW), Rhynchophorus ferrugienus, a new invasive coconut pest in Malaysia. Sains Malaysiana, 45(7), 1035-1040.
Sivapragasm A, Ngalim A, Razali B, Sukaime Ms. (2010). Field trapping of the adult red stripe weevil, Rhynchophorus vulneratus (Panzer) with an aggregation pheromone in a coconut ecosystem. The Planter, 86, 173180 .

Vidyasagar, P.S.P.V., Mohammed Hagi, Abozuhairah, R.A., AlMohanna, O.E. \& Al-Saihati, A.A. (2000). Impact of mass pheromone trapping on red palm weevil adult population and infestation level in date palm gardens of Saudi Arabia. Planter, 76 (891), 347-355.

Wahizatul, A. A., Zazali, C., Abdul, R., \& Nurul' Izzah, A. G. (2013). A new invasive coconut pest in Malaysia: the red palm weevil (Curculionidae: Rhynchophorus ferrugineus). Planter, 89 (1043), 97-110.

Wahizatul, A. A., Shahrol, N. D., Haris, M. H., Yong, K. W., Zazali, C., \& Ahmad, S. S. (2014). Field trapping of adult red palm weevil, Rhynchophorus ferrugineus olivier (Coleoptera: Curculionidae) with kairomone-releasing food baits and synthetic pheromone lure in a coconut plantation. Philippines of Agricultural Sciences, 97, 342-348.

Wahizatul, A. A., Zazali, Chong, J. L., Hazlina, A. Z., Norhayati, Y., Wan Bayani, W. O., Yong, K. W., Ainatun, N. Z., \& Haris, M. H. (2017). The red palm weevil Rhynchophhorus ferrugineus: current issues and challenges in Malaysia. Oil Palm Bulletin, 74, 17-24. 